\title{
Factors Affecting Hoteliers’ Decision to Advertise in Travel Magazine
}

\author{
Mohd Faiz Hilmi (Corresponding author) \\ School of Distance Education, Universiti Sains Malaysia \\ Gelugor 11800, Penang, Malaysia \\ Tel: +604-653-4560Ｅ-mail: mfhilmi@gmail.com
}

\author{
Ah Hwa Ngo \\ School of Distance Education \\ Universiti Sains Malaysia. \\ E-mail: ngousm@yahoo.com
}

Received: August 9, 2011 Accepted: August 23, $2011 \quad$ doi:10.5430/jms.v2n3p62

The research is partly financed by Incentive Grant from Universiti Sains Malaysia.

\begin{abstract}
Advertising is a paid, mass-mediated attempt to persuade. That mean Advertising is paid communication by a company or organization that wants its information disseminated through a communication medium designed to reach more than one person, typically a large number or mass of people and advertising includes an attempt to persuade consumer to like the brand and because of that liking to eventually buy the brand. Advertising in travel magazine is one of the promotional methods to promote hoteliers products or services to the market place. By advertising in travel magazine, it can reach the target audience, educate them about the products or services, and move them closer to make a purchase. The purpose of the research is to recognize and rank the factors affecting hotelier's decision to advertise in travel magazine. The respondents for the research are those hoteliers operating in Malaysia. The factors for this research are reached target readers, cost of advertising, contents of the magazine, frequency of advertising and media of advertising. The result of the research shows two of the factors significantly affecting hoteliers advertising decision. Furthermore, cost of advertising ranks the first follow by reach target readers, contents of magazine, media of advertising and frequency of advertising ranks the last. This research will help the publisher of travel magazine to understand and recognize the ranking of factors affecting hoteliers' decision to advertise in travel magazine.
\end{abstract}

Keywords: Marketing, Advertising, Travel Magazine and Hotel promotion

\section{Introduction}

Company must do more than make good products, they have to inform consumers about product benefits and carefully position their products in consumers' mind. To do this, they must skillfully employ the marketing communications or promotional mix. It is the specific mix of advertising, personal selling, direct marketing, sales promotion, and public relations that a company uses to pursue its advertising and marketing objectives. Promotion is one of the "P" under marketing mix. These 4 P's are the parameters that the marketing manager can control, subject to the internal and external constraints of the marketing environment. The goal is to make decisions that center the 4 P's on the customers in the target market in order to create perceived value and generate a positive response.

In this research, the focus is on the factors affecting hotelier decision to advertise in travel magazine. The research will be based on the information gather from hoteliers who are in the tourism industry in Malaysia. Since studying all the organizations in the tourism industry is just not feasible, this study will only focus on hotels and resorts located in Malaysia. The main reason for the focus on hotels and resorts in Malaysia because this tourism sectors generate the most income from the tourist and contribute income to nation.

Advertising is paid communication by a company or organization that wants its information disseminated through a communication medium designed to reach more than one person, typically a large number or mass of people. Advertising includes an attempt to persuade consumer to like the brand, and because of that liking, to eventually buy the 
brand. Besides, advertising also can be defined as any paid form of non-personal presentation and promotion of ideas, goods, or services by an identified sponsor. An advertising campaign is a series of coordinated advertisements that communicate a reasonably cohesive and integrated theme. The theme may be made up of several claims or points but should advance an essential singular theme. Successful advertising campaigns can be developed around a single advertisement placed in multiple media, or they can be made up of several different advertisements with a similar look, feel and message. In order to make the right decision to advertise in travel magazine, the hotelier must always study on the factors which make their advertisement cost effective and reach target readers.

\subsection{Research Problem}

Advertising is one of the important marketing promotion tools which enable customers, i.e., hoteliers, of the travel magazine to promote and position their product to the targeted readers. Due to this, all the hoteliers of the travel magazine are very sensitive and careful when selecting a media to advertise their product. The major stimulus for this study is to investigate the factors which affect hoteliers' decision to advertise in travel magazine.

Malay Mail on-line (4 May 2010) reported that despite 2009 being a challenging year for the tourism industry, Malaysia was listed in the top 10 by United Nations World Tourism Organization (UNMTO) in terms of tourist arrivals for the year 2009 (ninth place). It shows how competitive and popular Malaysia tourism businesses are in the world market. Besides, from the source of Immigration Department of Malaysia, the tourist arrivals from January to November 2008 is $19,993,804$ visitors, while in same period for 2009, the tourist arrivals is $21,505,120$ visitors. It shows an increase of $7.6 \%$ of tourist arrivals from 2008 to 2009 within the period.

Many tourism players in Malaysia are trying to attract and promote their product to the consumers and they are also looking for the factors which can make a return on investment on their advertisement that they has placed in a particular media. Magazine will be one of the media for them to advertise their product.

Following are the factors which affect hotelier decision on advertising:

1. Reach target readers - The targeted readers of the travel magazine who will be exposed to the advertising make by the customers. Reader here is referring to reader of the travel magazine and customer is referring to the hotelier of the travel magazine.

2. Cost of advertising - The cost of advertising space in the travel magazine refer to the cost pay for the size of an ad placed in a publication, for example a full page ad, half page ad or quarter page ad (either full colour or black and white, or any special techniques)

3. Contents of magazine - The contents of the magazine which attract consumers to read, for example the latest tourism hot spots, eco-tourism, homestays, rail tourism and others write up on tourism related articles.

4. Frequency of advertising - Determine how often we want the ad to run. This may vary depending on the lead time and publication frequency of the magazine. Many magazine publications print monthly, but some publish quarterly or randomly as need.

5. Advertising Media - There are a variety of advertising media from which to choose, for example broadcast media like television, radio and print media like newspaper and magazine.

\subsection{Research Objectives}

The objectives of the research are:

To investigate the impact/effect of factors (reach target readers; cost of advertising; contents of magazine; frequency of advertising and media of advertising) on hoteliers decision making in advertising in travel related publication

\subsection{Research Questions}

This research will be focusing on answering the following question:

Do the factors (reach target readers; cost of advertising; contents of magazine, frequency of advertising and media of advertising) affect hotelier's decision making in advertising in travel related publication?

\section{Factors Affecting Advertising}

Advertising in magazine is one of the promotional methods to promote the products or services to the market place. Advertisement in magazines can reach the target audience, educate them about the products or services, and move them closer to make a purchase. Most entrepreneurs find it worthwhile to explore the possibility of magazine advertising. The upside of magazine advertising can be summed up in one word; Image. While some advertising mediums (e.g. direct mail and newspapers) limit our ability to utilize high quality images to sell the product, with magazines the sky is the 
limit. Magazines allow for more complex layouts than newspapers and other more basic print alternatives. Even more, it provides the ability to showcase the product in full color, glossy format. This gives the customer's product a more polished feel and boots the credibility in the eyes of consumers. Another frequently overlooked upside of magazine advertising is that unlike other advertising mediums, magazines make it easy for customers to target specific market demographics. Most magazines have a very specific readership based on factors such as interests, age and gender. By leveraging readership demographics, it instantly ensures the message is being seen by the right people and the ones most likely to buy the product.

Traditional paid advertising media fall into two types: print and broadcast. Print involves printing words and pictures on a surface. Broadcast involves sending a signal with audio or video content to a receiving unit. Traditional print advertising media include magazines, newspapers, brochures, posters and flyers, billboards, Yellow Pages, and direct mail. Traditional broadcast advertising media include radio and TV. Magazine Display Ads Magazines can be divided into three types: news or general-interest magazines like Time and Newsweek, special-interest magazines like Cat Fancy or Easy Rider, and trade journals like Business Week or The Journal of the American Medical Association.

According to Danaher and Rust (1996) advertising is an investment and to maximize the return on investment, not all the allocated media budget should be spent and an optimal expenditure level must be calculated on the types of media which is going to use for advertisement purposes. While Bojanic (1991) mentioned that tourism is a major world industry and many countries rely on tourism revenues in their balance of payments. It is therefore imperative that a country convey a positive image to tourists. Preferences for tourism destinations are largely dependent on the favorableness of perceptions of those destinations and advertising is one of the most efficient means of conveying images.

\subsection{Reach Target Readers}

To select a media, the hotelier must decide what reach is needed to achieve advertising objectives. Reach is a measure of the percentage of people in the target market who exposed to the ad campaign during a given period of time. It means the targeted readers by the hotelier where their advertisement will be read by readers. For example the advertiser might try to reach 80 percent of the target market during the first three months of the campaign. The overwhelming advantages of magazines relative to other print or broadcast media are the ability of magazines to attract and target a highly selective audience. In our research, the travel magazine can be based on lifestyle or special interests media for the audience segment.

These days, there is tough competition in every field and new products and services are launched every day. In order to keep abreast of the competition, we need to educate the target customers regarding our products and services. Advertising in different media achieves this purpose very well. At the same time, advertising helps us to inform our clients that we are still around in spite of the new names emerging in the market everyday, we can segregate our target audience by geography and print our ads in only those magazines which are being propagated in a particular area. This will also help to keep the magazine advertising costs under check. We can also advertise in those magazines which cater to a particular interest group like sports magazines, health and fitness magazines, educational magazines etc. (Hayden, 2010). Therefore this study hypothesized;

\section{H1: Reach target readers is positively related to Advertising Decision}

\subsection{Cost of Advertising}

Cost is another main issue that the hotelier will consider. The cost of advertisement space, position to place the ad, for example Front cover, inside first page, Double page spreads, run-of-page, inside back cover or back cover and the placement of the ad in right or left hand pages are the main factors that an advertiser need to be consider. Magazines advertisement is quite cost effective, it offer a wide range of creative opportunities because of the ability to vary the size of an ad, use color, use black and white space and play off the special interests of the audience, magazines represent a favorable creative environment. Also because of the paper quality of most magazines is quite high, color reproduction can be outstanding. According to Dulsky (1933), the average person reads 5 to $10 \%$ of the copy of an ad and spends about 10 seconds looking at an advertisement. Younger people read less in an ad than adult and a smaller percentage of copy is read in the more wordy ads. Besides, more copy seems to be read on left-hand pages. While Strong Jr. (1914) said the value of space in advertising increases as the square root of the increase in area. Therefore this study hypothesized;

H2: Cost of advertising is positively related to Advertising Decision

\subsection{Contents of Magazine}

Perhaps more than any other medium, magazines attract an audience because of content. When a content of a magazine 
attracts a highly interested readership, advertisers, in turn, find a highly receptive audience for their brand messages. Contents of the travel magazine tell the consumers about what is inside the magazine. The travel magazine must be updated, innovative and must able to differentiate with other travel magazine which is selling in the market. It must include the latest tourism sectors like, Agro tourism, Eco tourism, Health \& Medical tourism, Education tourism, Homestay, MICE, Golfing, Sports Tourism, Malaysia Second Home programme and accommodation guides. Cleveland (2005) said the visual power is the degree of visual stimulus emanating from a given design; the higher the stimulus, the greater the degree for attracting attention in print materials. Caplin (2009) pointed out book and magazine publishing continues to flourish, despite dire predictions that the internet would kill them both. They also say that we may get our news from websites, but we get trusted opinion from magazines and it can surely be no coincidence that one of the world's top ranking websites is a book store. Therefore this study hypothesized;

H3: Contents of magazine is positively related to Advertising Decision

\subsection{Frequency of Advertising}

We all know that people forget most of what they learn in a relatively short period of time. In fact, most television and radio commercials are forgotten quickly after they air. That's why repetition is so important. Research shows that people need to see or hear a message three to five times before they become aware of it. And awareness continues to build with each exposure up to roughly 10 exposures. But, what about newspaper and magazine advertising? Is repetition important here, too? After all, a print ad is tangible. It can be clipped, saved and referred to over again. Research ever shows that increased frequency in magazine advertising dramatically improves ad awareness and effectiveness. In addition to increasing readership, advertising in multiple issues of a publication captures readers who may have missed or skipped our ad in a previous issue.

Strong. Jr. (1914) said the effectiveness of successive presentations depended upon the interval of time between the presentations. Which means the frequency of advertisement can be making in few interval periods in a year rather that advertise throughout the year. While Adams (1917) said on the effect of size and frequency of insertion of advertisements upon their memory value. It has been seen that when variations were used, repetition was much more effective than size. Greater effectiveness would be obtained by using small, varied advertisements, frequently inserted, than by employing larger ones with less frequency. Most of the advertisements seen are a mixture of variation and duplication. Therefore this study hypothesized;

H4: Frequency of advertising is positively related to Advertising Decision

\subsection{Media of Advertising}

There is a huge variety of media available through which a business can conduct an advertising campaign. What are the main types of media and what consideration should a business make in choosing between them? In order to get a right and effective way to promote and branding their products or services, the hotelier need to choose the most cost-effective media to get their message to the right people. They must evaluate and select the best advertising media to brand the products or services. The Media of advertisement are like television, radio, magazine, newspaper, internet, indoor or outdoor billboards and etc. The increasingly important role played by sponsorship or advertising in the marketing mix has given rise to the view that it should be considered a strategic activity with the potential to generate a sustainable competitive advantage in the marketplace (Fahy, Farrelly and Quester, 2004). Therefore this study hypothesized;

H5: Media of advertising is positively related to Advertising Decision

The hypothesized relationships are depicted in figure 1.

$$
<\text { Figure } 1 \text { about here> }
$$

\section{Method}

\subsection{Research Design and Procedure}

The survey method is deemed to be sufficient in obtaining the relevant data that will answer the research questions and objectives. Furthermore, survey method is popular and most common strategy in business and management research. Since the purpose of this study is to investigate the relationship between factors that affects advertising decision in travel magazine by hoteliers, as cross sectional research will be employed as the time horizon.

Systematic random sampling will be used in selecting the sample from a list of hotels and resorts listed in the Accommodation Guide 2009 of Malaysia. Survey questionnaires will be constructed and send to the selected hotels and resorts in Malaysia by using electronic mail (e-mail). From the e-mail, a link that will direct the respondent to a web survey site where they will be ask to answer all the questions stated in the questionnaire. Overall, this research should 
provide the understanding of the factors that affects advertising decision in travel magazine.

\subsection{Variable and Measurement}

The study used the five factors; reach target consumers, cost of advertising, contents of magazine, frequency of advertising and media of advertising as an independent variable to measure whether all of them have positive relation with advertising decision which is the dependent variable here. All the above factors were measured on a five-point Likert scale ( 1 = Strongly Disagree, 5 = Strongly Agree )

\subsection{Population and Sample}

The focus of this study will be on the organization. Consequently the unit of analysis will be the organization itself. The population of this study will be all hotel and resort in Malaysia. Obviously it is difficult to obtain the list of all the hotel and resort in Malaysia. Thus this study will depend on the Accommodation Guide 2009 of Malaysia as the population frame. The sample of the population will be the hotels and resorts in Malaysia. For this research study, a number of 85 sampling will be choose from the Accommodation Guide.

\section{Results}

\subsection{Profiles of Sample}

A total of 52 responses were obtained from 85 questionnaires. The profile of the organization and respondent are shown in table 1.

\section{<Table 1 about here>}

From table 1, it shows there are three types of business for the research organization, i.e., hotel, resort and hotel \& resort. 40 respondents (77\%) are in hotel business, 10 respondents (19.2\%) are in resort business and 2 respondents (3.8\%) are in hotel \& resort business. The hotel and resort business are rating by stars. 6 respondents (11.5\%) are working in two stars hotel, follow by 16 respondents (30.8\%) in three stars hotel, 15 respondents (28.8\%) in four stars hotel, 9 respondents (17.3\%) in five stars hotel, 3 respondents (5.8\%) particular in budget hotel and boutique hotel. The location of the organizations (hotel and resort) in this research is located inside the town, near the town or outside the town. $46.6 \%$ (24) of the 52 organization are located inside the town, 21.2\% (11) located near the town and 32.7\% (17) are outside the town.

All the organization (hotel/resort) in the research was established more than one year. 10 organization (19.2\%) were established within 1-5 years, 6 (11.5\%) were established within 6-10 years, 15 (28.8\%) were established between 11-15 years, $11(21.2 \%)$ were established within 16-20 years and 10 (19.2\%) were established from 21 years and above. In term of the numbers of rooms, 5 organizations (9.6\%) have between 10-50 rooms, 12 (23.1\%) have between 51-100 rooms, 16 (30.8\%) have between 101-200 rooms and 19 (36.5) organizations have 201 rooms and above. Out of 52 organizations (hotel/resort), 76\% (40) organizations are the members of Malaysian Association of Hotels (MAH) and the balance of $23.1 \%$ (12) are not MAH members.

A majority number of respondents, 31 (59.6\%) are working as manager or assistant manager. 16 respondents (30.8\%) are in executive kevel and 5 respondents (9.6\%) are organizations director or assistant director. 18 respondents (34.6\%) were working within 1-5 years, 12 (23.1\%) within working 6-10 years, 10 (19.2\%) within 11-15 years and 12 (23.1\%) were working 16 years and above.

\subsection{Reliability Analysis}

The first test carried out on the data was the reliability test on the multi-item instrumentals used in this research. The Cronbach's Alpha value was used to test the reliability of the items measuring each variable: reach target readers, cost of advertising, contents of magazine, frequency of advertising, media of advertising and advertising decision. It is a reliability measure coefficient that reflects how well items in a set are positively correlated to one another.

The result obtained as shown in table 2 indicates that the Cronbach's Alpha value for the measuring items of independent variables and dependent variable. The Cronbach’s Alpha for advertising decision was low at .661, it was accepted and considers as moderate as suggested in the rule of thumb about Cronbach's Alpha coefficient size (Hair, Babin, Money and Samouel, 2003). Reach target readers and frequency of advertising have Cronbach's Alpha between .7 to $<.8$, it's considered good in term of strength of association. Where else cost of advertising, contents of magazine and media of advertising have Cronbach's Apha between .8 to $<.9$, it is considered strong reliability. None of the items were deleted in the test, as the reliability of inter item was high.

$<$ Table 2 about here $>$ 


\subsection{Descriptive Analysis}

The summary of the descriptive statistic of the variables is given in table 3. All variables were measured in 5-point Likert scale from 1 to 5, where 1 represent strongly disagree and 5 being strongly agree.

$<$ Table 3 about here>

\subsection{Correlation Analysis}

Pearson Product-Moment Correlation coefficients was used to investigate the inter-correlations among all the study variables. Table 4 provide the summary of the results.

$<$ Table 4 about here>

\subsection{Regression Analysis}

The regression was run to determine the relationship between reach target readers, cost of advertising, contents of magazine, frequency of advertising, media of advertising toward advertising decision. Hypothesis H1a, H1b, H1c, H1d and H1e were tested at this stage. Table 5 list the result of multiple regression.

\section{$<$ Table 5 about here>}

Based on the regression analysis, approximately $62.4 \%$ variations of advertising decision can be explained by reach target readers, cost of advertising, contents of magazine, frequency of advertising, media of advertising. Hypotheses H1a (reach target reader is positively related to advertising decision) was accepted at $\mathrm{p}<.05$. Hypotheses H1c (contents of magazine is positively related to advertising decision) was accepted at $\mathrm{p}<.01$. The rest of the hypotheses were not accepted.

\section{Discussion and Conclusion}

\subsection{Discussion}

Based on the research result shown in table 6, cost of advertising is ranked as the main factor affecting hoteliers in advertising decision, follow by reach target readers, contents of magazine, media of advertising and the least important factor is frequency of advertising. The above ranking were finalized and ranked by 52 respondents from the questionnaire received.

\section{$<$ Table 6 about here>}

The study has shown reach target reader and contents of magazine have a significant positive relationship with advertising decision. This indicates that the publisher of a travel magazine must take into consideration the factor of reach target reader and contents of magazine because this factor will affect hoteliers advertising decision. Reach is measure of the percentage of people in the target market who exposed to the advertisement campaign during a given period of time and these day, there is tough competition in every field and new products and services are launched every day, so in order to keep abreast of the competition, we need to educate the target readers regarding our products and services (Hayden, 2010)

Contents of magazine has the strongest positive relationship with advertising decision and it was the most salient determinant of advertising decision with the highest beta value as compared to other independent variable. As compare to other advertising medium, contents of a magazine attract a highly interested readership, advertisers, in turn, find a highly receptive audience for their brand messages, visual power (Cleveland, 2005). Book and magazine publishing continue to flourish, despite dire predictions that the internet would kill them out (Caplin, 2009). Summary of the hypotheses acceptance are shown in table 7.

\section{<Table 7 about here>}

\subsection{Implication}

The implication of the study must be focus on the organization needs on advertising. We must able to find out the factors affecting hoteliers decision to advertise in travel magazine. With that we will be able to handle and form effective strategies to persuade our customers to advertise. The implication of this study shows that the reach target reader and contents of magazine is the key factor affecting hoteliers for advertising decision. Most of the respondents from the survey agree that cost of advertising of the travel magazine affected their decision to advertise their advertisement. A reasonable advertising cost may attract more advertisers to advertise. Besides, the hoteliers also concern on the reach target readers of the travel magazine. The magazine publisher must be able to manage and reach the travel magazine to the targeted readers, getting more readerships. Contents of magazine and media of advertising are another two factors taking into consideration by the hoteliers before making the advertising decision. Both of these factors are important 
because it will attract readers interest to read and buy the media. A good and quality magazine always has it readers. Frequency of advertising is not significant for hoteliers to make advertising decision, as this factor is not the key factor to influence them to advertise in the travel magazine.

\subsection{Limitations}

Despite the useful findings of this study, the empirical study has several limitations that need to be acknowledged. First, the findings cannot be generalized extensively in all the state in Malaysia, as the scope of the study is confined to the state of Sabah, Labuan, Sarawak, Langkawi, Penang, Perak, Selangor, Putrajaya, Kuala Lumpur, Negeri Sembilan and Pahang. Therefore caution may be needed before generalizing the findings to the whole country. Secondly, the findings in this study depend on the honesty, working experience, knowledge, and length of services in the industry and the position of the respondent in the particular organization. It is known individual would agree more on socially desirable answers and disagree more towards socially undesirable answers rather than fully and truly express the feeling and opinions. Some of the respondents may lack of working experience and knowledge or not fully involve in company business strategies may not answering the questionnaire well.

Thirdly, due to time and resources constraints, the study is limited as it consists of a small sample size of 52 out of 85 respondents who replied the e-mail of the questionnaire, i.e., within two months period. Finally, the periods to send out the questionnaire by e-mail to respondents are important. The respondent (Director, Manager or Executive personnel) of the hotel and resort is normally very busy with their work during peak seasons like public and school holidays. This happen particular in the month of January to March, June, September and November to December. So, we must given enough time for them to answer the questionnaire, say within half year period.

\subsection{Conclusion}

The findings of the research conclude that reach target reader and contents of magazine are determinants of advertising decision. The rest of the factors were found to be insignificant in affecting hoteliers decision to advertise in travel magazine. Questionnaire was used to collect data from the respondent. 85 questionnaires were e-mailed to the respondents, however only 52 respondents able to complete and reply the e-mail. The result also shows cost of advertising was ranked as the top factor affecting hoteliers advertising decision. It follows other factor reach target readers, contents of magazine, media of advertising and frequency of advertising was less popular among the independent factors.

\section{References}

Adams, H. F., (1917). The memory value of mixed sizes of advertisements. Journal of Experimental Psychology, 2 (6), 448-465. http://dx.doi.org/10.1037/h0073381

Bojanic, David C. (1991). The use of advertising in managing destination image. Tourism Management, 12 (4), 352-355. http://dx.doi.org/10.1016/0261-5177(91)90047-W

Caplin, Steve (2009). Books and Magazines. Art and Design in Photoshop, (pp. 127-151).

Cleveland, Paul (2005). How much visual power can a magazine take? Design Studies, 26 (3), $271-317$. http://dx.doi.org/10.1016/j.destud.2004.05.007

Danaher, P. J. and Rust, R. T., (1996) Determining the optimal return on investment for an advertising campaign. European Journal of Operational Research, 95 (3), 511-521. http://dx.doi.org/10.1016/0377-2217(95)00319-3

Dulsky, S.G., (1993). Factors influencing the amount of copy read in "magazine” advertisement, Journal of Applied Psychology, 17 (2), 195-204. http://dx.doi.org/10.1037/h0073613

Fahy, J., Farrelly, F. and Quester, P., (2004). Competitive advantage through sponsorship: A conceptual model and research propositions, 28 (8), 1013-1030

Hayden, J., (2010). Newspaper and Magazine Advertising for Maximum Customer Reach. Retrieved 13 November 2010 , from

http://ezinearticles.com/?Newspaper-and-Magazine-Advertising-For-Maximum-Customer-Reach\&id=4321034

Strong Jr., Edward K. (1914). Effect of size of advertisement and frequency of their presentation. Psychological Review, 21 (2), 136-152. http://dx.doi.org/10.1037/h0072562 
Table 1. Organization and Respondent Profile

\begin{tabular}{|c|c|c|}
\hline Demographic & Frequency & Percentage \\
\hline \multicolumn{3}{|l|}{ Type of business } \\
\hline Hotel & 40 & 77 \\
\hline Resort & 10 & 19.2 \\
\hline Hotel \& Resort & 2 & 3.8 \\
\hline \multicolumn{3}{|l|}{ Hotel/Resort Star Rating } \\
\hline Two Stars & 6 & 11.5 \\
\hline Three Stars & 16 & 30.8 \\
\hline Four Stars & 15 & 28.8 \\
\hline Five Stars & 9 & 17.3 \\
\hline Budget Hotel & 3 & 5.8 \\
\hline Boutique Hotel & 3 & 5.8 \\
\hline \multicolumn{3}{|l|}{ Location of hotel/resort } \\
\hline Inside the town & 24 & 46.1 \\
\hline Near the town & 11 & 21.2 \\
\hline Outside the town & 17 & 32.7 \\
\hline \multicolumn{3}{|c|}{ How long the hotel/resort has been establish } \\
\hline $1-5$ years & 10 & 19.2 \\
\hline $6-10$ years & 6 & 11.5 \\
\hline $11-15$ years & 15 & 28.8 \\
\hline 16-20 years & 11 & 21.2 \\
\hline 21 years and above & 10 & 19.2 \\
\hline \multicolumn{3}{|c|}{ Number of rooms the hotel/resort has } \\
\hline $10-50$ & 5 & 9.6 \\
\hline $51-100$ & 12 & 23.1 \\
\hline $101-200$ & 16 & 30.8 \\
\hline 201 and above & 19 & 36.5 \\
\hline \multicolumn{3}{|l|}{ Your designation } \\
\hline Director/Asst. Director & 5 & 9.6 \\
\hline Manager/Asst. Manager & 31 & 59.6 \\
\hline Executive & 16 & 30.8 \\
\hline \multicolumn{3}{|c|}{ Years of services in the hotel/resort industry } \\
\hline $1-5$ years & 18 & 34.6 \\
\hline $6-10$ years & 12 & 23.1 \\
\hline $11-15$ years & 10 & 19.2 \\
\hline
\end{tabular}




\begin{tabular}{|c|c|c|}
\hline Demographic & Frequency & Percentage \\
\hline 16 years and above & 12 & 23.1 \\
\hline & & \\
\hline Are your resort/hotel is a member of $M A H$ & & \\
\hline Yes & 40 & 76.9 \\
\hline No & 12 & 23.1 \\
\hline
\end{tabular}

Table 2. Reliability Analysis

\begin{tabular}{|l|c|c|c|}
\hline \multicolumn{1}{|c|}{ Factor Label } & \# of Items & Item Deleted & Reliability \\
\hline Reach target readers & 8 & - & .704 \\
\hline Cost of advertising & 9 & - & .822 \\
\hline Contents of magazine & 9 & - & .879 \\
\hline Frequency of advertising & 8 & - & .712 \\
\hline Media of advertising & 8 & - & .832 \\
\hline Advertising decision & 8 & - & .661 \\
\hline
\end{tabular}

Table 3. Descriptive Analysis

\begin{tabular}{|c|c|c|}
\hline Variable & Mean & Standard Deviation \\
\hline Reach target readers & 4.0000 & .43654 \\
\hline Cost of advertising & 3.7821 & .46829 \\
\hline Contents of magazine & 4.2222 & .50127 \\
\hline Frequency of advertising & 3.6034 & .45152 \\
\hline Media of advertising & 3.7260 & .49510 \\
\hline Advertising decision & 4.0481 & .36895 \\
\hline
\end{tabular}

Table 4. Correlation Analysis

\begin{tabular}{|c|c|c|c|c|c|c|}
\hline & 1 & 2 & 3 & 4 & 5 & 6 \\
\hline Reach target readers & 1 & & & & & \\
\hline Cost of advertising & 0.260 & 1 & & & & \\
\hline Contents of magazine & 0.503 & 0.540 & 1 & & & \\
\hline Frequency of advertising & 0.471 & 0.514 & 0.594 & 1 & & \\
\hline Media of advertising & 0.395 & 0.556 & 0.530 & 0.646 & 1 & \\
\hline Advertising decision & 0.552 & 0.443 & 0.751 & 0.473 & 0.344 & 1 \\
\hline
\end{tabular}

Note: $\quad * * \mathrm{p}<.01, \quad * \mathrm{p}<.05$ 
Table 5. Regression Analysis

Note: $* * \mathrm{p}<.01, \quad * \mathrm{p}<.05$

\begin{tabular}{|c|c|}
\hline Independent Variable & Beta \\
\hline Reach target readers & $.259^{*}$ \\
\hline Cost of advertising & .118 \\
\hline Contents of magazine & $.635^{* *}$ \\
\hline Frequency of advertising & .030 \\
\hline Media of advertising & -.180 \\
\hline & \\
\hline R Square & .624 \\
\hline Adjusted R Square & .583 \\
\hline F Changes & 15.275 \\
\hline Durbin-Watson & 1.961 \\
\hline
\end{tabular}

Table 6. Ranking of Factor Affecting Advertising Decision

\begin{tabular}{|c|c|}
\hline Factor & Ranking \\
\hline Reach target readers & 2 \\
\hline Cost of advertising & 1 \\
\hline Contents of magazine & 3 \\
\hline Frequency of advertising & 5 \\
\hline Media of advertising & 4 \\
\hline
\end{tabular}

Table 7. Summary of Results

\begin{tabular}{|c|c|c|}
\hline Hypothesis & Result & Beta Value \\
\hline $\begin{array}{c}\text { Reach target readers is positively related } \\
\text { to Advertising Decision }\end{array}$ & Accepted & .259 \\
\hline $\begin{array}{c}\text { Cost of Advertising is positively related } \\
\text { to Advertising Decision }\end{array}$ & Not Accepted & .118 \\
\hline $\begin{array}{c}\text { Contents of Magazine is positively } \\
\text { related to Advertising Decision }\end{array}$ & Accepted & .635 \\
\hline $\begin{array}{c}\text { Frequency of Advertising is positively } \\
\text { related to Advertising Decision }\end{array}$ & Not Accepted & -.180 \\
\hline $\begin{array}{c}\text { Media of Advertising is positively } \\
\text { related to Advertising Decision }\end{array}$ & Not Accepted & \\
\hline
\end{tabular}




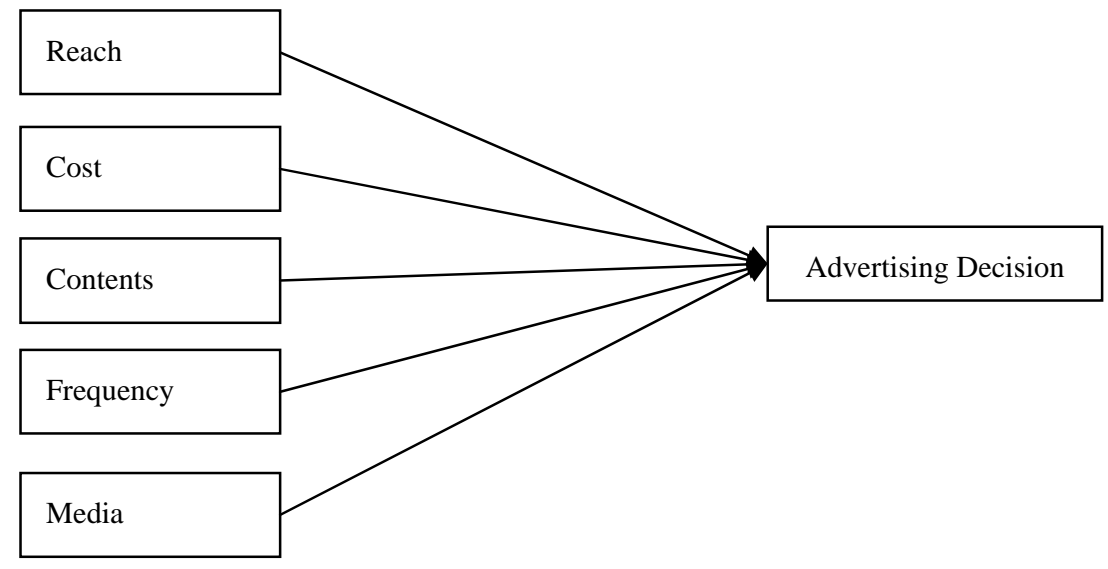

Figure 1. Schematic Diagram of Research Framework 